\title{
Demandas de autenticidad: deseo, ambivalencia y racismo en el Chile multicultural
}

\author{
Demands of authenticity: desire, ambivalence and racism in \\ multicultural Chile
}

\author{
Antonieta Vera / averag@docentes.academia.cl \\ https://orcid.org/0000-0001-5865-1621 \\ Universidad Academia de Humanismo Cristiano y Universidad de Chile, Chile \\ Isabel M. Aguilera / iaguilera@uta.cl \\ https://orcid.org/0000-0002-0534-4369 \\ Universidad de Tarapacá, Chile \\ Rosario Fernández / rosario.fernandez@gold.ac.uk \\ https://orcid.org/0000-0003-3724-8678 \\ Goldsmiths-University of London, United Kingdom
}

\begin{abstract}
This article aims to characterize the production and the creation of value of ethnic/ racial otherness in the context of neoliberal multiculturalism in Chile based on a theoretical work around the concepts of otherness, representation, ambivalence and authenticity. From this perspective and through qualitative methods, we will analyze three concrete examples framed in research projects: the ethno-enterprise, domestic labor and the allegoric-bodies of tradition. Our main analysis result is that the demands for authenticity perceived by subjects marked as Others in Chile display a demand to correctly act or perform a role, which in spite of being stereotyped, may or not be appropriated by the Others. Our proposal concludes stating the following thesis: the demands for authenticity constitute the crystallization of contemporary racism in Chile.
\end{abstract}

Key words: multiculturalism, otherness, racism, ambivalence, authenticity.

Resumen: Este artículo busca caracterizar la producción y puesta en valor de la otredad étnico/racial en el marco del multiculturalismo neoliberal en Chile, a partir de un trabajo teórico en torno a los conceptos de otredad, representación, ambivalencia y autenticidad. Desde esta clave de lectura y a través de metodologías cualitativas, analizaremos tres ejemplos concretos enmarcados en investigaciones en curso: las etnoempresas, el trabajo doméstico y los cuerpos-alegóricos de la tradición. El principal resultado del análisis es que las demandas de autenticidad precibidas por los sujetos marcados como Otros en Chile develan una exigencia de actuar correctamente un papel, que -aunque estereotipado- puede o no ser reapropiado por los Otros. Nuestra propuesta concluye enunciando una tesis: las demandas de autenticidad constituirían una configuración contemporánea del racismo en Chile.

Palabras clave: multiculturalismo, otredad, racismo, ambivalencia, autenticidad. 


\section{Introducción}

El presente texto constituye un trabajo de reflexión teórica y de carecterización de la producción y puesta en valor de la Otredad étnico-racial en el contexto del multiculturalismo neoliberal en Chile. En la época actual, en la cual el concepto "raza" ha dejado de tener la legitimidad que tuvo durante el siglo XIX y gran parte del XX, asistimos a un tipo particular de racismo que ha sido denominado por diversos autores como "racismo neoliberal sin raza" (Wade, 2011), "racismo institucional de rostro pluralista" (Hale, 2004) o "racismo cultural” (Balibar y Wallerstein, 1991). Este racismo contemporáneo se vincularía al actual modelo de gestión de las diferencias: el multiculturalismo neoliberal (Hale, 2004; Zizek, 1998).

Su novedad contrasta, sin embargo, con la persistencia de una relación ambivalente de deseo y rechazo de Otredad que hoy se vería expresada en ciertas demandas de autenticidad que definirían los términos de la relación Nosotroslos Otros. Así, identificando algunos momentos claves de la construcción de la diferencia étnico/racial, profundizaremos conceptualmente en el problema de la representación del Otro, interrogando las continuidades y discontinuidades involucradas en la actual puesta en valor de la Otredad.

La primera parte de este trabajo está redactada en tercera persona y la última parte, en primera persona, debido a que el enfoque que las autoras desarrollan aquí es producto de una trayectoria compartida en el equipo "Nación, Otredad, Deseo", plataforma de investigación interdisciplinar, al interior de la cual hemos desarrollado perspectivas de diálogo y análisis comunes para abordar los fenómenos de las migraciones contemporáneas y la etnogubernamentalidad en Chile. Asimismo, cada una de las autoras ha sido la investigadora responsable de uno de los tres proyectos a partir de los cuales hemos construido la última parte del texto.

El trabajo se divide entonces en cuatro partes, de las cuales las tres primeras se orientan a discutir los pilares conceptuales de nuestra propuesta: raza, multiculturalismo, representaciones y autenticidad. En la primera señalaremos las coordenadas generales del debate sobre la multiculturalidad, identificando como antecedente clave el giro conceptual raza-etnia, así como el correlato histórico-político que le acompaña: del asimilacionismo al multiculturalismo neoliberal. En la segunda parte profundizaremos en la problemática de las relaciones de poder que enmarcan la representación de la Otredad, consignando el carácter histórico y productivo del ambivalente deseo y rechazo del Otro. 
En el tercer apartado interrogaremos el momento del multiculturalismo neoliberal actual, a partir de lo que sostenemos sería una de las formas claves de su ambivalente producción de otredad: las demandas de autenticidad. En la cuarta sección, desarrollaremos tres ejemplos que emanan de las investigaciones de cada una de las autoras del texto ${ }^{1}$ y que ilustrarían la discusión teórica desarrollada en los tres apartados anteriores: "Etnoempresa y negociación de lo auténtico", “Trabajo doméstico y élites: la nostalgia de la 'buena nana” e "Indias permitidas: alegorías de la autenticidad". Los primeros dos ejemplos emanan de resultados de investigación, y el tercero corresponde a una de las hipótesis de trabajo de una investigación en fase inicial. Finalmente y a modo de conclusión, consignaremos algunas de las claves de lectura y la perspectiva de investigación que el presente texto deja abiertas.

\section{Multiculturalismo neoliberal. El lugar de la Otredad hoy}

Los discursos en torno a "los Otros de la nación" constituyen una de las formas centrales de construcción de la diferencia tanto en el contexto colonial como republicano en América Latina. En esa línea, es necesario consignar la centralidad del concepto "raza" al momento de pensar en los proyectos nacionales decimonónicos. En el contexto de la secularización y una vez que la ciencia sustituye a la teología como régimen de verdad, el lenguaje del determinismo biológico se convierte en el más legítimo para "representar la raza” (Leys-Stepan, 1991; Knight, 1990). Sin embargo, tras los horrores del nazismo, la categoría "raza" caerá en desuso en varios contextos nacionales (Arias y Restrepo, 2010; Varikas, 1998) y comenzará a ser paulatinamente reemplazada por el concepto "etnicidad", que para Hall es "el término que nosotros damos a los rasgos culturales - lenguaje, religión, costumbre, tradiciones, sentimientos por un 'lugar' - que son compartidos por un grupo" (Restrepo, 2004: 106).

Sin embargo, el concepto raza sigue portando un tipo de especificidad distinta a la del concepto etnicidad. Segato (2007: 23) señala que la raza es un signo, una "huella en el cuerpo del paso de una historia otrificadora que

1 Este artículo se enmarca dentro de tres proyectos: Proyecto PAI núm. 821320053 "Patrimonialización de la cocina indígena en Chile: procesos de alterización, diferenciación y apropiación”, de Isabel Aguilera, financiado por CONICYT/PAI; “Trabajo doméstico pagado en Chile: performances de lo íntimo y lo político en hogares de élite”, de Rosario Fernández financiado por Becas Chile de CONICYT; Proyecto FONDECYT núm. 11160588 "Mapuche eco-espiritual: políticas de la diferencia género-racializada en el multiculturalismo neoliberal”, de Antonieta Vera. 
construyó 'raza' para constituir 'Europa' como idea [...] que distribuye valor y significado en nuestro mundo”. Para Varikas (1998), uno de los efectos más problemáticos del giro conceptual raza-etnia es la minimización de la persistencia del racismo en las sociedades de posguerra.

Como señala Varikas:

El cambio terminológico no conlleva necesariamente un cambio en la realidad ni en las maneras de percibirla [...] agregándose a la raza (o al color) la etnicidad (con su contenido pretendidamente cultural) fue considerada como un criterio distinto de estratificación social ocultando el hecho que las dos categorías a menudo hacían parte de un mismo sistema de dominación que obtenía su legitimación de la naturalización y de la inferiorización de diferencias reales o imaginarias (Varikas, 1998: 91-92).

Por su parte, Menard (2012: 5) señala otro efecto del desplazamiento conceptual raza-etnia: la descorporización vehiculizada por el concepto etnicidad. Ésta aludiría a "la imposibilidad de contar con un objeto acabado -como era el cuerpo racializado - para aprehender la alteridad como una totalidad".

El giro conceptual raza-etnia ha tenido también un correlato político en América Latina. Tras los genocidios y esclavización de poblaciones enteras, se pusieron en marcha políticas asimilacionistas fundadas en la inclusión del Otro vía blanqueamiento racial y cultural. Así, la primera mitad del siglo XX latinoamericano se caracterizó por "la ideología del mestizaje", una ideología estatal que promovía un pacto social de inclusión y, paralelamente, demandaba la asimilación a un ideal mestizo y homogéneo como sujeto de identificación nacional (Knight, 1990; Zermeño-Padilla, 2008). Pero la ideología del mestizaje no es simplemente una cuestión de etnicidad. En la medida que el mestizaje alude a la reproducción y el control de la sexualidad, el "nosotros nacional” no sólo implicará la producción de un orden racial, sino también de un orden de género (Stoler, 2013).

En la segunda mitad del siglo XX, las críticas a los discursos y políticas asimilacionistas cristalizarán en un nuevo modelo de gestión de las diferencias: el multiculturalismo. El llamado "problema de la diversidad cultural", visibilizado por los procesos migratorios posteriores a la Segunda Guerra Mundial y por la racialización de las "costumbres" y religiones de los migrantes en Europa (Demorgon, 1998), por las reivindicaciones regionales anglo/ francófonas en Canadá (Esses y Gardner, 1996), por las políticas migratorias del melting pot en Estados Unidos (Banks, 1995; Sleeter y Grant, 1988) y por lo que se ha denominado la cuestión indígena en América Latina (Sieder, 2002; Van-Cott, 2000), implicó el desarrollo de un modelo multicultural que se proponía hacer frente a los conflictos y desigualdades generadas a partir de estas transformaciones culturales, promoviendo simultáneamente la tolerancia y el respeto por la diferencia. 
Sin embargo, desde comienzos de los noventa, se hacen evidentes los efectos esencialistas y/o despolitizadores que -en la práctica- tuvieron las políticas multiculturales en el contexto neoliberal. Así, autores como Zizek (1998) o Hale (2004) propondrán pensar el multiculturalismo neoliberal como un modelo que promueve políticas de respeto por un Otro folclórico y/o esencializado, pero que en la práctica termina excluyendo al Otro, acusado de fundamentalista, terrorista y/o ajeno a los intereses de la nación. Para Zizek (1998: 172-179), el multiculturalismo constituye "una forma de racismo negada, invertida, autorreferencial, un 'racismo con distancia': 'respeta' la identidad del Otro, concibiendo a éste como una comunidad 'auténtica' cerrada, hacia la cual él, el multiculturalista, mantiene una distancia que se hace posible gracias a su posición universal privilegiada".

Desde el punto de vista de Hale (2004), la principal paradoja del multiculturalismo neoliberal es la tensión entre derechos culturales y derechos político-económicos. Entendiendo que el énfasis del multiculturalismo en América Latina se ha puesto en los derechos indígenas, Hale sostiene que si bien éstos abren y legitiman nuevos espacios de participación, las políticas multiculturales también imponen límites tajantes a cambios económicos transformadores. Es a partir de esa constatación como Hale (2004: 19) identifica al "Indio permitido" como categoría sociopolítica: aquel que negocia con la modernidad, cambia la protesta por la propuesta, aprende a "actuar con autenticidad, ${ }^{2}$ y a la vez, a manejar el lenguaje dominante". "El Indio permitido" necesariamente producirá a su Otro, el "Indio insurgente": el rebelde, vengativo, terrorista. El efecto político más problemático de estas políticas multiculturales neoliberales es, por lo tanto, promover un régimen representacional que redunda en el empoderamiento de ciertos sectores indígenas y, simultáneamente, en la marginalización y empobrecimiento de otros.

Historizando en esta misma línea, Segato (2016) sostiene que tras la caída del Muro de Berlín, la agenda antisistema se transforma en la agenda inclusiva del multiculturalismo: el problema ya no sería el sistema sino cómo incluirlo en el sistema. Así, una vez reconocida la existencia de minorías de poder, la medida ha sido crear élites de cada una de estas minorías, élites parciales de mujeres, indígenas, homosexuales y proletarios, incluidas en la medida en que "cada una trajera sus plumas". Años antes, Hardt y Negri (2002: 174) habían deslizado más o menos la misma idea: "el Imperio" permite el libre juego de las diferencias y las tolera "en la medida en que cada uno acepte obrar de acuerdo con esas diferencias de identidad, en la medida en que cada uno 'represente' a su raza...".

2 El énfasis es nuestro. 
Las políticas multiculturales exigen, producen y celebran la diferencia en tanto reducto de "originalidad" y "autenticidad". Desde este enfoque, podemos situar también las reflexiones de autores como Briones (2005) y Comaroff y Comaroff (2011), quienes llaman la atención sobre los efectos del multiculturalismo neoliberal en términos de fetichización y mercantilización de la Otredad. El contexto donde se inserta nuestra reflexión alude justamente a las nuevas formas de racismo consolidadas a partir del modelo multicultural neoliberal: aquello que Hale (2004) vincula a una institucionalidad pluralista que reconstituye jerarquías raciales, lo que Balibar y Wallerstein (1991) entienden como racismo cultural, lo que Wade (2011: 25) señala como "un racismo neoliberal sin raza" o lo que Zizek (1998) denomina "racismo postmoderno contemporáneo".

Pensar el racismo en este contexto, evidencia el carácter marcadamente ambivalente del mismo (entre celebración y opresión, entre deseo y rechazo). Sabemos que tal como lo han señalado los estudios poscoloniales a partir de investigaciones en torno al exotismo o la intimidad en los regímenes coloniales (Bhabha, 1994; Stoler, 2013), la ambivalencia del racismo no constituye por sí misma una cuestión contemporánea. Sin embargo, es en la época de un "racismo sin raza" en la que nos interesa pensar el carácter productivo de dicha ambivalencia.

\section{Representaciones y deseos ambivalentes de Otredad}

El deseo de Otredad en el contexto global de las relaciones de poder NorteSur ha dependido históricamente de fantasías e imaginarios en los cuales es posible identificar representaciones género-racializadas (McClintock, 1995; Ahmed, 2000). Por ejemplo, McClintock (1995) ha analizado con precisión la tradición porno-trópica del imperialismo europeo a partir de la cual los sujetos “descubiertos" en África y América son clasificados en términos sexuales y raciales, promoviendo imaginarios, representaciones y estereotipos que trabajaron en pos de la producción de Otredad.

En el escenario multicultural contemporáneo es posible reconocer la fuerza histórica y emocional de este tipo de representaciones y estereotipos, operando de manera ambivalente en el nivel del deseo. En este sentido, nos interesa destacar dos carácterísticas de estas representaciones: su resistencia al paso del tiempo y su capacidad de portar posibilidades simultáneas de idealización y ultraje (Bhabha, 1994).

Hall (2013) señala que el discurso de "Occidente y el Resto" implica un modo particular de representar la diferencia entre Europa y los "Otros", que 
tiende a la simplificación y estereotipación. Según Hall (2013: 92), un estereotipo es el producto de una práctica representacional a partir de la cual "diferentes características son reunidas y condensadas en una sola. Esta exagerada simplificación es luego acoplada a un sujeto o lugar. Sus características se convierten en los signos, en la 'evidencia' por medio de los cuales un sujeto es conocido. Ellos definen su ser, su esencia”.

El estereotipo, a su vez, está dividido en dos mitades opuestas (inocentedepravado; noble-innoble; amistoso-caníbal): "esta es la forma en que la estructura profunda del estereotipo refleja las ideologías sociales y políticas de la época” (Hall, 2013: 94). Así, las representaciones hegemónicas del Otro no suponen siempre y en todo lugar una condensación de signos negativos; al contrario, y tal como indica Wade (2009: 37): "Mientras el otro es definido como diferente e inferior y, por tanto, como real o potencialmente amenazante, el otro puede también ser visto como misteriosamente atractivo, fascinante y poderoso". ${ }^{3}$

La persistencia y la eficacia de este tipo de representaciones dependen, en suma, del simultáneo deseo y rechazo de la otredad (Bhabha, 1994). Así lo señala con claridad Bhabha (1994: 91), para quien la plasticidad y resistencia al paso del tiempo de las representaciones estereotipadas depende de su naturaleza ambivalente: "Es este proceso de ambivalencia $[. .$.$] lo que [. .$.$] asegura$ su repetibilidad en coyunturas históricas y discursivas cambiantes; conforma sus estrategias de individuación y marginalización; produce ese efecto de verdad probabilística y predictibilidad...”.

La ambivalencia produciría así relaciones de poder y de subjetivación especialmente paradójicas para los subalternos. Para dar cuenta de esta problemática a nivel teórico, Elsa Dorlin (2007) sugiere pensar tanto la subjetivación paradojal a la que se enfrentarían los subalternos, como la lógica común entre sexismo y racismo. La autora sostiene que la imitación no sólo revela la dependencia subjetiva del colonizado/a. Tal como lo afirmara Fanon (1973), el estereotipo se transforma en la escena en la cual se interpreta la subjetivación del colonizado, su acceso al estatuto o a la posición de sujeto, pero también la del colonizador: es el blanco quien produce al "negro", y el "negro", así reificado, el que produce al "blanco".

Las representaciones estereotipadas implican entonces una relación social que, sin lugar a dudas, no sólo produce la otredad, sino que también la mismidad. Si bien las representaciones estereotipadas pueden reforzar relaciones de poder hegemónicas, de su carácter ambivalente también pueden

3 Cabe señalar que de aquí en adelante todas las traducciones del inglés y del francés son nuestras. 
emerger posibilidades de agenciamiento (Bhabha, 1994; Irigaray, 2009), que develan el carácter mutuamente significativo y/o potencialmente transformador del reconocimiento. Ahora bien, tal como insiste McClintock (1995: 63-64), las posibilidades de subversión de la ambivalencia no deben ser sobreestimadas: "Localizar la agencia en la ambivalencia corre el riesgo de lo que puede llamarse un fetichismo de la forma: la proyección de la agencia histórica en abstracciones formales que son antropomorfizadas y a las que se les otorga vida propia”. En resumen, es necesario problematizar e historizar los usos de la ambivalencia para entender cuándo y cómo estas estrategias pueden llegar (o no) a ser subversivas.

\section{Demandas de autenticidad: deseo de Otredad, deseo de reconocimiento}

Para autores como Comaroff y Comaroff (2011), la valorización contemporánea de la Otredad como "mercancía escasa" o "fetiche" refiere necesariamente al aura de un pasado. En efecto, los investigadores señalan que el aura de los objetos históricos "es un fenómeno producido exclusivamente por la distancia [...] Es la distancia de lo esquivo, sea en el tiempo o en el espacio" (Comaroff y Comaroff, 2011: 48). Es esta distancia la que se ha hecho "añicos" en la modernidad, época cuya tendencia será "considerar equivalentes todas las cualidades, 'acercar las cosas' y asirlas consumiendo un calco de ellas mecánicamente reproducido” (Idem). Desde allí, Comaroff y Comaroff (2011: 47) sostienen que el "otro aborigen" puede servir como "complemento" para el turista-consumidor global: "un sustituto para su propia falta de autenticidad ${ }^{4}$ cultural y plenitud".

Desde una perspectiva similar, Hooks (1992) propone leer el gusto por el Otro en tanto expresión de una "nostalgia imperialista": un lamento por un pasado destruido que los propios destructores expresan, mistificando al mismo tiempo tal pasado y sugiriendo que los Otros constituyen una reserva de lo perdido. Según Hooks (1992: 369), la cultura de masas movilizaría la nostalgia imperialista a través de representaciones y ritualizaciones en las que los Otros operan como "proveedores de alternativas de vida". Desde esta mirada, el consumo de otredad no es simplemente sustitutivo, sino nutritivo y potencialmente transformador; "dentro de la cultura de la mercancía, la etnicidad se convierte en especia, en condimento que puede avivar el aburrido plato de la cultura blanca hegemónica" (Hooks, 1992: 366). El deseo de Otredad remitiría así a una búsqueda por mejorar lo propio a través del consumo de lo ajeno.

4 El énfasis es nuestro. 
Los análisis de Comaroff y Comaroff (2011) y Hooks (1992) sugieren que buena parte de lo que está en juego en los encuentros con los Otros es la llamada "autenticidad existencial" (Steiner y Reisinger, 2006; Wang, 1999; Handler, 1986). El contacto con la alteridad (y su consumo) se configurarían en una puerta de entrada hacia un sí mismo "verdadero" (Wang, 1999: 358), "fiel a su naturaleza" (Steiner y Reisinger, 2006: 299), liberado del juego de roles que impone la cotidianidad (Handler, 1986). Así, las demandas por autenticidad estarían ligadas a la emergencia de un ideal propio de las sociedades modernas, caracterizado por la nostalgia o el romanticismo:

Es nostálgica porque idealiza las formas de vida en las que supuestamente las personas son más libres, más inocentes, más espontáneas, puras, y verdaderas a sí mismas que lo usual [...] También es romántica porque acentúa la naturalidad, los sentimientos, y las emociones en respuesta a la creciente auto-constricción generada por la razón y la racionalidad en la modernidad (Wang, 1999: 360).

Sin embargo, precisamente porque se trata de un encuentro, la emergencia de la autenticidad existencial no puede sino estar ligada a la autenticidad del Otro o, si queremos, al éxito de la negociación conducente a percibir al otro como un auténtico Otro. Efectivamente, desde una aproximación construccionista, la autenticidad "no es una propiedad inalterable de un objeto o situación, sino un atributo que se negocia” (Comaroff y Comaroff, 2011: 49). En esa negociación emerge lo que Culler (1981) ha llamado "autenticidad simbólica” y que refiere a experienciar a los Otros (sus prácticas y objetos asociados) como auténticos, en tanto son percibidos como signos o símbolos de autenticidad.

La autenticidad percibida poco tiene que ver con lo real y mucho con la proyección y el deseo, de ahí que los más estrechos estereotipos puedan vehiculizar sentidos de autenticidad en tanto satisfacen las creencias, expectativas y preferencias de quienes la demandan. De este modo, una representación bien ejecutada o una simulación genuina y rigurosa desde el punto de vista histórico, puede ser percibida y acogida como auténtica (Bruner, 1994). Nada hay más lejos de esta postura que la noción de engaño. Si creemos, junto con Bruner, que la autenticidad no es algo dado o la característica propia de algún objeto, sujeto o situación, sino aquello que emerge de un proceso social no ajeno al poder, podríamos pensar que la autenticidad se acerca mucho más a la hegemonia que a la falsedad.

Como veremos más adelante, las demandas de autenticidad que reciben los sujetos marcados como Otros en Chile se acercan mucho a la exigencia de actuar o performar correctamente un papel, pero se trata de un rol que aunque prediseñado, estereotipado y escrito desde posiciones hegemónicas, 
puede o no ser reapropiado por los Otros. Nuestra tesis es que en el contexto del multiculturalismo neoliberal en Chile, una de expresiones del racismo ambivalente corresponde a las demandas de autenticidad que hemos conceptualizado aquí. Tal demanda apelaría al rescate de tradiciones y valores anclados en un pasado perdido, encarnado actualmente por sujetos indígenas, migrantes y/o rurales que se ven interpelados/as a desplegar performances género-racializadas de autenticidad, las cuales tienen por objeto -al menos en primera instancia- satisfacer el deseo de Otredad y, paralelamente, posibilitar la obtención de diversos tipos de reconocimiento que permiten inteligibilidad existencial y/o sobrevivencia material.

\section{Etnoempresa, trabajo doméstico e indias permitidas: dilemas de autenticidad}

\section{Etnoempresa y negociación de lo auténtico}

Las etnoempresas, turísticas y de alimentación son relativamente nuevas en el sur de Chile; de hecho, en 2008, la oficina regional del Servicio Nacional de Turismo no contaba con folletos que promocionaran las pequeñas iniciativas turísticas de familias mapuche. En general, la microempresa étnica no es una actividad económica muy extendida entre los mapuche, ni constituye la actividad principal de las familias, sino que se trata de un negocio que complementa los ingresos derivados de la pequeña agricultura. En términos generales, todos estos emprendimientos emergen de una coproducción entre diversos agentes estatales, microempresarios mapuche y organismos no gubernamentales (ONG) y han sido impulsados por los gobiernos postransicionales como una herramienta para alcanzar el desarrollo (Aguilera, 2016).

La cualidad étnica de las empresas depende de dos cuestiones. Por un lado, el negocio debe ser propiedad de personas legalmente reconocidas como mapuche y, a la vez, "formalizadas" como microempresarias. Por otro lado, la oferta debe originarse de la transformación de productos y prácticas culturales definidas como propiamente mapuche en mercancía, por ejemplo: vestuario, alimentación, arquitectura, medicina, música y danza, entre otras.

La cuestión de la autenticidad cobró relevancia durante el trabajo de campo, aunque se trata de situaciones excepcionales. Según mis observaciones, anfitriones y visitas se embarcan comprometidamente en el encuentro pactado que supone el turismo (Bruner, 2005). Como si ambas partes fueran conscientes de estar en una borderzone $e^{5}$ la magia del encuentro amoroso y

5 Espacio de encuentro entre turistas y nativos, donde se crea activamente cultura y se realiza 
comprensivo con la otredad impregna la actividad turística. Sin embargo, pequeños detalles desatan desacuerdos en torno a la representación y aparecen, a veces de manera muy explícita, demandas de autenticidad.

En una "ruka turística" cercana a la ciudad de Villarrica, la construcción fue ligeramente modificada. En lugar de cubrir toda la circunferencia superior con junco o junquillo se dejaron dos espacios, como tragaluces, cubiertos con paneles plásticos. Uno de los objetivos de los gestores de la ruka era exponer ahí el trabajo en telar de las mujeres de la comunidad y, por lo tanto, la luz (la posibilidad de ver) era fundamental. Las rukas son viviendas que en su versión sancionada como original no tienen ventanas, son espacios más bien sombríos. Aunque la ruka en cuestión tenía bastantes más elementos que no se ajustaban al original, como por ejemplo una pequeña construcción interna que albergaba una cocina, fue la modificación arquitectónica la que movilizó una disputa que según un informante fue en los siguientes términos.

El visitante le indicó a su anfitrión que las rukas no eran así, que él lo sabía y que existía material consultable que lo respaldaba. El anfitrión habría contestado algo parecido a esto: Soy mapuche, hago la ruka como quiero. La segunda experiencia no corresponde exactamente al ámbito del turismo, pero sí al de la etnoempresa y fue vivida por una mujer que se dedicaba a ofrecer "cocteles interculturales"6. Durante años esta empresaria ofreció servicio de catering a diferentes instituciones privadas y públicas de La Araucanía. En uno de esos eventos, una de las participantes se le acercó para felicitarla, pero al mismo tiempo para preguntarle por qué no se vestía "como mapuche".

Podemos traducir esa frase de este modo: ¿porqué no usa trarilonko ${ }^{7}$, trapelacucha ${ }^{8}$, cintas de colores en el pelo y un rebozo?, es decir aquello que se ha estabilizado como la vestimenta mapuche. Para la informante, ese tipo de vestimenta es "de gala" y se usa sólo en ocasiones señaladas, no para ir a trabajar. Además, según me indicó, después de cocinar le da tiempo para una ducha rápida y salir hacia el lugar del evento y no alcanzaría a vestirse con lo que llama "toda la indumentaria". Pero la negativa a vestirse como mapuche no tenía que ver solamente con cuestiones práticas ni ajustarse a los contextos. Esta microempresaria consideraba que muchos de sus colegas ofrecían una

una teatralización donde cada actor desarrolla un papel predeterminado durante un tiempo definido (Bruner, 2005).

6 Un coctel intercultural se compone de una variedad de bocados y bebidas, algunos de los cuales se consideran mapuche y otros no mapuche.

7 Adorno frontal formado por colgantes discales.

8 Adorno pectoral formado de dos piezas centrales unidas por tres eslabones. 
imagen folclórica de los mapuche que ella no comparte, una imagen, según dijo riendo, very typical.

Ambos ejemplos informan sobre los tipos de autenticidad en juego en los encuentros cruzados por el consumo de otredad. En el primero, la sospecha pesa sobre un objeto, una materialidad; mientras que en el segundo se enjuicia la performance étnica. En el caso de la ruka, lo que se exige es la correcta representación, es decir, rigurosa desde el punto de vista histórico. En el caso del vestuario, se exige una puesta en escena más acabada, capaz de hacer vivir el contacto con la otredad de un modo más intenso.

Ambas situaciones pueden analizarse desde un punto de vista construccionista de la autenticidad, en la medida que se abre una negociación en torno al éxito de la representación, el cual depende de la capacidad de los microempresarios mapuche de ajustarse a unas formas estéticas que pudiendo serles propias han sido estabilizadas y sancionadas como lo mapuche. El caso de la negociación referida al vestuario ejemplifica con claridad aquello que Culler (1981) llama "autenticidad simbólica": pareciera como si la mujer que ofrece el coctel intercultural no pudiera operar como signo de autenticidad y, por lo tanto, imprimir ese carácter al conjunto de la puesta en escena.

Las respuestas frente a las demandas de autenticidad son algo diferentes en los dos ejemplos, pero en ambos prevalece la lógica del derecho a la autorrepresentación. La identidad y la adscripción étnica legitiman una representación que tuerce el original histórico, que se basa en la selección de elementos y en la producción activa de nuevos objetos y prácticas mapuche. Pero no se trata de una identidad estática ni única, que haga honor a los libros de etnohistoria y a la versión tradicionalizada y eco-friendly del indio permitido. La mapuchidad es un argumento de autoría y autoridad, y el contenido de esa identificación así como la reflexividad en torno al sí mismo varía según el microempresario de que se trate.

De ahí que la crítica sobre versiones más o menos folclorizadas de la mapuchidad se ejerza entre los propios mapuche. En el marco del multiculturalismo normativo, el desajuste entre la representación hegemónica y una autorrepresentación que, aun sirviéndose de una serie de elementos estandarizados, deja abiertos grados de libertad para la interpretación de la cultura mapuche, genera un ruido, una tensión que se expresa en preguntas y reclamos que los etnoempresarios deben gestionar.

Las respuestas a esas demandas informan sobre una disputa mayor sobre la producción, la propiedad y el control sobre lo mapuche. Construir pensando en un objetivo práctico (la visibilidad), definir cuándo es apropiado usar qué tipo de vestuario y cómo resulta más cómodo trabajar, son cuestiones 
que devienen problemáticas porque está en juego el consumo de otredad y porque se desea una otredad familiar, apropiable, digerible. Esa es la otredad que se puede percibir como auténtica, valiosa e inocua. Cuando los y las empresarios/as étnicos performan la otredad según los términos que ellos mismos han definido se produce una especie de desencuentro entre anfitriones y turistas, que paradójicamente es producto de lo que en principio anima el etnoturismo: la diferencia entre ambos.

\section{Trabajo doméstico y élites: la nostalgia de la "buena nana"}

El trabajo doméstico pagado y las trabajadoras domésticas, nombradas en Chile de forma peyorativa nanas, constituyen mi caso de estudio, el cual da cuenta de las formas actuales como opera el racismo y la producción de otredad a través de la distinción de buenas y malas nanas (Fernández, 2017). Para comprender cómo se actualiza el deseo por buenas nanas y el rechazo por aquellas consideradas malas, es importante entender la demanda actual por el trabajo doméstico. Existe hoy una alta demanda por trabajo doméstico pagado (Stefoni y Fernández, 2011), que ha sido atribuida a la "crisis de los cuidados", aquella crisis provocada por la falta de provisión estatal de servicios de cuidados a niños, niñas y adultos mayores.

Sin embargo, estudios sugieren que las empleadoras advierten de la emergencia del "problema de la nana” (Staab y Mahler, 2005; Hutchison, 2011), referido a las dificultades de encontrar auténticas buenas nanas, pues hoy las trabajadoras domésticas chilenas vendrían de orígenes supuestamente marcados por pobreza y violencia, y conocerían y exigirían mucho sus derechos, convirtiéndolas en malas nanas. Así lo señalaba la página web de la empresa Proyecto Nanas (2014), dedicada a la provisión de trabajadoras domésticas de origen filipino, en el año 2014 (página actualmente modificada), refiriéndose a las trabajadoras chilenas:

Generalmente son mujeres que luchan por superar la pobreza y los flagelos que la acompañan como el abandono de la pareja, la cesantía, la violencia intrafamiliar. Frente a esta difícil realidad emplearse como nana parece ser una buena opción; pero ¿están preparadas para ejercer esta delicada labor? (Proyecto Nanas, 2014).

Frente al "problema de la nana" (Staab y Mahler, 2005), emerge hoy una demanda por recuperar a la buena nana, la nana permitida, la cual respondería no a una "crisis de los cuidados", sino a una nostalgia y expectativa -por parte de las y los empleadores de clases acomodadas- de que las tareas de cuidado y de "servicio" sean realizadas por "auténticas sirvientas". Dichas sirvientas son representadas por una memoria -que se distancia de la realidad (Stoler, 
2009) - por cuerpos dóciles de mujeres indígenas y mestizas, reactivando una nostalgia por el poder señorial y rural previo a las reformas agrarias. Así, no cualquier mujer sería adecuada para tales funciones.

Diversas mujeres, en su condición de otredad racial, étnica y de clase, ocuparían las preferencias de los empleadores a lo largo del tiempo, culminando hoy en la nana migrante. Mientras en el siglo XX eran preferidas las "niñas del sur" -un eufemismo para referirse a mujeres provenientes de sectores rurales e indígenas-, a partir de la década de 1990 las inmigrantes latinoamericanas (especialmente peruanas) se volverían más deseadas por la supuesta disposición sumisa y dócil que su "origen" otorgaría (Stefoni y Fernández, 2011). Si las "niñas del sur" daban cuenta de una historia de racialización de mujeres pobres, indígenas y rurales chilenas, hoy convertidas en malas nanas por su insurrección, las nanas inmigrantes reflejan un nuevo proceso de racialización de mujeres que emerge con la feminización de la migración hacia Chile, especialmente en su flujo Sur-Sur, pero ahora también de orígenes filipinos.

A su vez, las buenas nanas supuestamente realizarían sus funciones respetando los deseos de las y los empleadores con auténtico cariño, devoción y actitud servicial, sin nunca perder la conciencia de su lugar subordinado dentro de los hogares (Fernández, 2017). Es una demanda no sólo por un servicio, sino principalmente por una experiencia con la otredad: la nana sería capaz de performar un acto de entrega servicial marcado por una economía afectiva (Gutiérrez, 2010), que garantiza su autenticidad manteniendo las relaciones de poder. Serían, en especial, las peruanas, y últimamente las filipinas, quienes comienzan a suplir esta demanda, pues en ellas las empleadoras encontrarían las cualidades perdidas en las nanas chilenas; su "auténtica" actitud servicial junto con sus privilegiados conocimientos culinarios y sus modos cariñosos con los niños, convertirían a mujeres peruanas y filipinas en las nanas deseadas por las empleadoras. Así también lo señalaba Carol Luco, directora de Proyecto Nanas en una entrevista realizada en noviembre de 2014 por la autora de este texto: "Las filipinas son reconocidas por su abnegada labor con los niños, por su actitud de servicio, por ser trabajadoras, disciplinadas, reconocen a la autoridad y tienen buena capacidad de adaptación" (entrevista a Carol Luco en noviembre de 2014).

Luco (2014) señala que su empresa brinda una experiencia de bienestar para los y las empleadores, al proveerles nanas serviciales y cariñosas. De este modo, las trabajadoras filipinas como otras mujeres migrantes son llamadas a performar a la "auténtica buena nana", a través de estereotipos de género y raciales, demanda que se materializa en la exigencia por un trabajo afectivo 
(Gutiérrez, 2010) -hacer el aseo con una "buena cara", sonreír a los empleadores, mostrar auténtico cariño por los niños-y destacando su otredad étnico-racial, mediante su expertice culinaria.

Frases como "la nana peruana es más querendona" o "la nana filipina cocina exquisito, ideal para invitados" -escuchadas en mis entrevistas con empleadoras- marca el "origen" de estas mujeres -en contraposición a mujeres de otros orígenes nacionales- como las nanas perfectas al servicio de las clases acomodadas. Así, la otredad de las mujeres inmigrantes, filtrada por la sociedad de acogida, es explotada y convertida en un valor para el trabajo de servidumbre.

Por tanto, la distinción buenas/malas nanas refleja el simultáneo deseo y rechazo por la figura de la trabajadora doméstica, por una mujer marcada por su otredad de clase, étnica y racial. Se refiere específicamente al deseo por la buena nana, inspirada en la figura idílica de la sirvienta -históricamente representada por mujeres chilenas indígenas y rurales (Hutchinson, 2011)-, y que hoy se apropia del cuerpo de la mujer migrante latinoamericana y filipina, la cual es deseada en tanto cuerpo "dócil y sumiso" que posibilita la reproducción del estatus de clase y racial de las familias de clases acomodadas, y al rechazo de la mala nana -encarnada en la figura de mujeres chilenas de sectores urbanos, indígenas y pobres-, en tanto no se asimila a las necesidades de los hogares, convirtiéndose en elemento peligroso por su "origen".

Tanto la buena como la mala nana se configuran a partir de la división sexual y racial del trabajo que se instala con el sistema moderno/colonial de género (Lugones, 2008), el cual edifica estereotipos coloniales basados en la diferencia racial, étnica y de género (McClintock, 1995), que son rearticulados hoy en términos de "origen". En el contexto del racismo cultural chileno actual, la diferencia de "origen" obtiene valor positivo en la medida en que mujeres inmigrantes actúen y se comporten como "buenas" servidoras de las familias acomodadas chilenas y de la nación.

Ahora, el simultáneo deseo y rechazo no sólo da cuenta del modo de operar del racismo en Chile con mujeres inmigrantes, sino que también es una forma como los empleadores reedifican su distinción de "origen" (de clase y étnico/racial) en el contexto de un Chile multicultural, donde la diferencia obtiene valor por estar al "servicio" del nosotros nacional. La diferenciación entre empleadoras y trabajadoras, la acentuación de la "distancia" y el continuo proceso de convertir a las trabajadoras en otredad al "servicio de", son formas en que las y los empleadores sostienen y naturalizan su distinción.

Pareciera ser, entonces, que la demanda por la nana migrante refleja la búsqueda de nuevas formas de diferenciación étnico/racial y de clase que 
posibiliten, simultáneamente, la supuesta superioridad, condición de privilegio y el derecho a ser servidos de las clases acomodadas. De este modo, a través de las demandas por nanas que muestran auténtico deseo por hacer su trabajo, conocer su lugar subordinado y ser trabajadoras eficientes, las y los empleadores son capaces de rearticular nuevas nociones modernas de sí mismos sin perder sus privilegios del pasado. Es en el encuentro cotidiano con las nanas migrantes que los y las empleadoras negocian y encuentran su "auténtica" autoridad y superioridad de étnico/racial y de clase.

\section{Indias permitidas: alegorias de autenticidad}

El acercamiento teórico a partir del cual he iniciado mi proyecto de investigación, se aboca en gran medida a la problematización de la representación de la raza/etnia mapuche y de las políticas de la diferencia a ella vinculadas en el contexto multicultural actual.

La cuestión de la representación de la raza ha constituido una problemática clave de la historia colonial y poscolonial, que ha develado los valores morales implicados en la construcción de la diferencia. Tal como señalábamos siguiendo a Menard (2012), una de las consecuencias del giro conceptual raza-etnia es la progresiva descorporización vehiculizada por el concepto etnicidad. Mi intención es pensar la dimensión generizada de este fenómeno. Efectivamente, en la medida en que las representaciones hegemónicas de la feminidad en Occidente han aludido de una u otra manera a las mujeres como cuerpos-sexuados-reproductores, tal descorporización no dejaría de tener efectos particulares para las mujeres indígenas.

Si tal como lo señala Stoler (2013), las ansiedades coloniales y republicanas de Occidente se focalizaron de manera transversal en la sexualidad de colonizados y colonizadores, poniendo un especial énfasis en el control de los cuerpos susceptibles de producir a otro cuerpo dentro de sí, es porque la sexualidad es capaz de construir y borrar fronteras raciales tanto a nivel metafórico (iconografía de la jerarquía), como a nivel material (los cuerpos como la sustancia misma de los proyectos coloniales-nacionales).

En la época en la que el concepto "raza" hacía total sentido a las intelligentsias latinoamericanas, las representaciones hegemónicas de las mujeres mapuches hicieron alusión a las conveniencias e inconveniencias del mestizaje. Así, serán tildadas por Vicuña Mackenna de "brujas maléficas" (Zárate, 2007), por los sacerdotes capuchinos de "semi-salvajes, llenas de supersticiones y víctimas de la poligamia", a quienes habría que elevar "al alto nivel de la mujer civilizada que disfruta al amparo de las leyes, la religión y de la sociedad 
civil cristiana" (Foerster y Montecino, 1988: 171), o por ensayistas como Tomás Guevara (1911), de mujeres impúdicas, extremadamente fáciles y con un bajo desarrollo moral.

En el contexto multicultural latinoamericano actual, una de las formas paradójicas de puesta en valor de "lo étnico" se expresa en una ambivalente demanda de autenticidad cultural que remitiría al imaginario de una ancestralidad rural, espiritual y ecológica (Vera, 2016). Siguiendo a autoras como Varikas (2007) o Stoler (2013), es posible sostener que las mujeres han sido históricamente representadas como reproductoras biológicas y simbólicas de la nación, marcadores de la tradición, la naturaleza y el territorio de un pueblo. En esa medida, la demanda de autenticidad develaría su carácter generizado (Vera, 2016).

Específicamente en relación con el contexto latinoamericano, diversas investigaciones señalan que en tanto portadoras de la lengua materna, las vestimentas y las costumbres, la eficacia simbólica de las mujeres para representar "lo indígena", es mayor (De la Cadena, 1992; Pequeño, 2007). Así, la encarnación de la tradición implicaría para las mujeres indígenas la adquisición de un capital político relevante respecto a la demanda de autenticidad de las políticas multiculturales. Los efectos ambivalentes de ese capital aludirían a la descorporeización vehiculizada por la "etnicidad" como categoría que dota de inteligibilidad a "la raza" en tiempos multiculturales.

Desde un análisis preliminar de fuentes primarias y secundarias a nivel latinoamericano, es posible identificar la ambivalencia señalada en la aplicación de políticas indígenas. Por ejemplo, en espacios interculturales como el etnoturismo, "el retorno a las tradiciones indígenas es presentado como una esperanza para la gente urbana” (Ulloa, 2005: 101). De manera específica, las mujeres son representadas como portadoras de una sabiduría ancestral vinculada al manejo de hierbas, conocimientos medicinales y a una espiritualidad femenina ligada a la Madre Tierra (Radcliffe, 2008; Donato et al., 2007).

En el caso mapuche y a partir del retorno a la democracia, Bacigalupo (2010) ha llamado la atención sobre la reiterativa aparición mediática de la machi. La presentación pública del cuerpo femenino mapuche -con su vestimenta tradicional y su kultrung- opera como marcador de autenticidad de la cultura, legitimando con ello el pacto con presidentes y ministros de Estado (Vera, 2014). Así también, analizando la puesta en marcha del Programa Orígenes en Chile, Bascopé (2009) ha mostrado cómo estas políticas reforzaron la figura de la machi como garante de la continuidad cultural. En esa misma línea, entre las licitaciones convocadas en el último tiempo durante el 2015 por la Corporación Nacional de Desarrollo Indígena (CONADI), es interesante 
identificar la promoción del uso de la vestimenta tradicional entre mujeres mapuche a través de solicitudes de "proveedores de aros" o "suvenires"; o el llamado a "promover los derechos de las mujeres indígenas del Bío-Bío", a partir del desarrollo de un "emprendimiento con identidad cultural" y la "promoción de prácticas ancestrales” entre las mujeres (CONADI, 2014).

"Mantente alegoría de la ancestralidad", pareciera ser la versión contemporánea de la nostalgia imperialista (Hooks, 1992) en estas escenas de celebración de la diversidad cultural. Ancestralidad normativamente alegórica, ya que cuando ésta muestra su materialidad a partir del vínculo con el territorio (un cementerio, unos árboles sagrados, un terreno donde crecen ciertas yerbas, un paisaje y unas formas de vivir) y, por ende, con el conflicto con las empresas forestales, la femineidad indígena alegórica es reemplazada por los cuerpos concretos de Macarena Valdés, Lorenza Cayuhan o Francisca Linconao. ${ }^{9}$

Si a fines del siglo XIX y comienzos del XX, la mismidad requería del cuerpo-sexuado-impúdico de las mujeres mapuche para construir las fronteras étnico/raciales, hoy requeriría de la descorporización de esas mujeres para sostener la representación de una ancestralidad idealizada e intraductible, de la cual depende el Nosotros-los Otros nacional. Así entonces, utilizando el binomio de Hale (2004) desde una perspectiva feminista decolonial, sugerimos que el régimen representacional de "la India permitida" depende de una demanda de autenticidad sostenida por el imaginario de una ancestralidad rural, espiritual y ecológica representada con gran rendimiento político por el cuerpo femenino mapuche.

Cuando esa ancestralidad inmaterial deviene materialidad a partir de un cuerpo femenino que exige derechos políticos y económicos, emerge la

9 Estos casos son sólo algunos ejemplos de una situación histórica y de mayor envergadura localizada en el conflicto en La Araucanía entre las comunidades mapuche y las empresas forestales y/o familias dueñas de la tierra en el sur de Chile. Macarena Valdés era esposa del werkén mapuche Rubén Collío, con quien lideraba la resistencia del proyecto hidroeléctrico de la empresa austríaca RP Global, en la comunidad de Tranguil. Fue encontrada ahorcada en su casa. El informe de su autopsia ha sido cuestionado por miembros del Colegio Médico de Chile. Por su parte, el caso de Lorenza Cayuhan, se conoció cuando en noviembre de 2016 fue encarcelada. Lorenza da a luz a su hija Sayén, engrillada de los pies. El Colegio Médico y el Instituto Nacional de Derechos Humanos corroboraron que la situación violaba una serie de tratados internacionales ratificados por Chile. Finalmente, el caso de la machi Francisca Linconao se hizo conocido en el marco de la investigación de la muerte del empresario Werner Luchsinger y su esposa Vivianne Mackay. A fines de 2016, Linconao -quien siempre ha alegado inocencia- inició una huelga líquida. Diversas organizaciones feministas y de mujeres mapuche la apoyaron y exigieron un pronunciamiento formal del Sevicio Nacional de la Mujer. 
"India insurrecta", la terrorista. El desafío de pensar las políticas desde una perspectiva dinámica de la cultura se volverá especialmente relevante para las mujeres mapuches, cuyas experiencias y cuerpos desborden la demanda de la autenticidad ancestral.

\section{A modo de conclusión}

Raza, como concepto y como forma de marcación, es una bisagra que permite vincular desde el punto de vista teórico ciertas continuidades en la representación y valoración de la alteridad, específicamente la cuestión del deseo ambivalente, con fenómenos propiamente contemporáneos como la nostalgia imperialista y la búsqueda de la autenticidad existencial. Repensar el racismo en tiempos etnicistas y "sin raza”, supone analizar de manera crítica el marco ideológico y político que ha definido las relaciones de alteridad en los últimos cincuenta años, el multiculturalismo, así como una revisión de las lógicas representacionales que han cruzado históricamente esas relaciones. A ambas cuestiones nos hemos referido en los dos primeros apartados de este artículo, y, en este sentido, sólo quisiéramos insistir en un aspecto.

El multiculturalismo neoliberal, tal como ha sido definido en las páginas precedentes, no es simplemente un concepto descriptivo, sino una forma político-ideológica de gestionar diferencias étnico-raciales. El modelo es productivo, crea y reafirma representaciones tanto de "nosotros" como de "los otros", al mismo tiempo que estabiliza y legitima las formas posibles y deseables de representación y autorrepresentación. Independiente del contenido exacto de cada una de esas representaciones, nuestra tesis es que merecen ser leídas desde las aproximaciones que ven en el deseo la clave para comprender las relaciones de alteridad. Rechazar y desear al otro es un hilo que puede tensarse más o menos, pero que no desaparece ni siquiera en el contexto de exaltación de la diversidad que caracteriza al multicuralismo en Chile; al contrario, esa exaltación bien puede movilizar el deseo.

Como hemos sostenido, el multiculturalismo tiene un correlato económico y moral. La otredad encarnada en cuerpos y prácticas gana valor, se mercantiliza, se transa y ofrece de diversas maneras, pero todas ellas llevan el signo de la diferencia. De la intraductibilidad de la diferencia dependen su valor y su autenticidad. El tercer apartado, dedicado al concepto autenticidad, pone sobre la mesa la necesidad de prestar atención al proceso de negociación que define los encuentros basados en la búsqueda de la diferencia. En esa negociación se devela tanto el deseo de otredad y de autenticidad como las posibilidades de autorrepresentación pensables y consumibles. 
Por último, a través de nuestros ejemplos hemos dado cuenta de cómo se presenta concretamente y en la vida cotidiana la tensión deseante, la búsqueda de autenticidad, la nostalgia y la lucha por la representación. Cada uno de ellos pone énfasis diferentes; sin embargo, se encuentran en una mirada común: aquella que ve en las relaciones de alteridad, actuales y corrientes, las trazas del racismo. La perspectiva en la cual nos proponemos seguir investigando es justamente ésta: las demandas de autenticidad constituirían la cristalización del racismo contemporáneo en la medida en que estarían demarcando las formas permitidas, deseables, recompensables, financiables y reconocibles de ser y no ser.

\section{Referencias}

Aguilera, Isabel (2016), De la cocina al Estado nación. El ingrediente mapuche, España: Icaria, Observatorio de la alimentación.

Ahmed, Sara (2000), Strange Encounters: Embodied Others in Post-Coloniality, Inglaterra: Routledge.

Arias, Julio y Restrepo, Eduardo (2010), "Historizando raza: propuestas conceptuales y metodológicas", en Crítica y Emancipación, año 2, núm. 3, Argentina: CLACSO.

Bacigalupo, Ana-María (2010), "Las prácticas espirituales de poder de los machi y su relación con la resistencia mapuche y el Estado chileno", en Revista Chilena de Antropología, núm. 21, Santiago: Universidad de Chile.

Balibar, Etienne y Wallerstein, Immanuel (1991), Race, Nation, Class. Ambiguous Indetities, Inglaterra: Verso.

Banks, James (1995), "Multicultural Education: Historical Development, Dimensions, and Practice", en Banks, James [ed.], Handbook of research on multicultural education, Estados Unidos: MacMillan.

Bascope, Joaquin (2009), La invasión de la tradición. Lo mapuche en tiempos culturales, Chile: Colibris Ediciones.

Bhabha, Homi (1994), The Location of Culture, Inglaterra: Routledge.

Briones, Claudia (2005), "Formaciones de alteridad: contextos globales, procesos nacionales y provinciales", en Briones, Claudia [comp.], Cartografias argentinas: politicas indigenas y formaciones provinciales de alteridad, Argentina: Antropofagia.

Bruner, Edward (1994), "Abraham Lincoln as Authentic Reproduction: A critique of postmodernism”, en American Anthropologist, vol. 96, núm. 2, Estados Unidos: American Anthropological Association.

Bruner, Edward (2005), Culture on tour. Etnographies of travel, Estados Unidos: The University of Chicago Press.

Comaroff, John y Comaroff, Jean (2011), Etnicidad S.A, España: Katz Editores.

CONADI (Corporación Nacional de Desarrollo Indígena) (2014), Chile: Ministerio de Desarrollo Social, Gobierno de Chile. Disponible en: www.conadi.cl [22 de noviembre de 2014].

Culler, Jonathan (1981), "Semiotics of Tourism", en American Journal of Semiotics, núm.1, Estados Unidos: Semiotic Society of America. 
Antonieta Vera, Isabel M. Aguilera y Rosario Fernández . Demandas de autenticidad: deseo, ambivalencia y racismo en el Chile multicultural

De La Cadena, Marisol (1992), "Las mujeres son más indias. Etnicidad y género en una comunidad del Cusco”, en Revista ISIS Internacional, núm.16, Santiago: Ediciones de la mujer.

Demorgon, Jacques (1998), L'histoire Interculturelle des Societés, Francia: Anthropos.

Donato, Luz-Marina et al. [eds.] (2007), Mujeres indigenas, territorialidady biodiversidad en el contexto latinoamericano, Colombia: Universidad Nacional de Colombia.

Dorlin, Elsa (2007), "Performe ton genre, performe ta race!”. Disponible en: www.sophia. be [24 de octubre 2008].

Esses, Victoria y Gardner, Robert (1996), "Multiculturalism in Canada: Context and current status”, en Canadian Journal of Behavioural Science, vol. 28, núm. 3, Canadá: Canadian Psychological Association.

Fanon, Frantz (1973), Piel negra, máscaras blancas, Argentina: Ediciones Abraxas.

Fernández, Rosario (2017), "Trabajo doméstico pagado: la 'solución perfecta' para la 'familia feliz' en Chile”, en Pavez, Jorge [ed.], (Des) orden de género. Politicas y mercados del cuerpo en Chile, Chile: CRANN Editores.

Foerster, Rolf y Montecino, Sonia (1988), Organizaciones, lideres y contiendas mapuches 1900-1970, Chile: Centro de Estudios de la Mujer.

Guevara, Tomás (1911), Folklore Araucano, Chile: Imprenta Cervantes.

Gutiérrez, Encarnación (2010), Migration, domestic work and affect: a decolonial approach on value and the feminization of labor, Inglaterra: Routledge.

Hale, Charles (2004), "Rethinking indigenous politics in the era of the "indio permitido", en NACLA Report on the Americas, vol. 38, núm. 2, Estados Unidos: The North American Congress on Latin America.

Hall, Stuart (2013), “Occidente y el resto: discurso y poder”, en Soto, Ricardo [ed.], Discurso y poder en Stuart Hall, Perú: Biblioteca Nacional del Perú.

Handler, Richard (1986), "Authenticity”, en Anthropology Today, vol. 2, núm. 1, Reino Unido: Royal Anthropological Institute.

Hardt, Michael y Negri, Antonio (2002), Imperio, España: Paidós Ibérica.

Hooks, Bell (1992), Black Looks: Race and Representations, Estados Unidos: South End Press.

Hutchinson, Elizabeth (2011), "Shifting Solidarities: The Politics of Household Workers cold war Chile”, en Hispanic American Historical Review, vol. 91, núm. 1, Inglaterra: Duke University Press.

Irigaray, Luce (2009), Ese sexo que no es uno, España: Ediciones Akal.

Knight, Alan (1990), “Racism, Revolution and Indigenismo: Mexico, 1910-1940”, en Graham, Richard [ed.], The idea of Race in Latin America 1870-1940, Estados Unidos: University of Texas Press.

Leys-Stepan, Nancy (1991), The Hour of Eugenics. Race, Gender, and Nation in Latin America, Estados Unidos: Cornell University Press.

Lugones, María (2008), “Colonialidad y género”, en Tabula Rasa, núm. 9, Colombia: Universidad Colegio Mayor de Cundinamarca.

Mcclintock, Anne (1995), Imperial Leather: Race, Gender, and Sexuality in the Colonial Contest, Estados Unidos: Routledge.

Menard, André (2012), "El culto moderno a los indígenas (o el retorno de los indios espirituales)", en Malestar y destinos del malestar. Disponible en: https://www.researchgate. net/publication/277009596_El_culto_moderno_a_los_indigenas_o_el_retorno_ de_los_indios_espirituales[30 de noviembre 2014]. 
Convergencia Revista de Ciencias Sociales, núm. 76, 2018, Universidad Autónoma del Estado de México

Pequeño, Andrea (2007), Imágenes en disputa. Representaciones de mujeres indigenas ecuatorianas, Ecuador: Abya-Yala.

Proyecto Nanas (2014). Disponible en: www.proyectonanas.cl [2 de noviembre de 2014].

Radcliffe, Sarah (2008), "Las mujeres indígenas ecuatorianas bajo la gobernabilidad multicultural y de género", en Wade, Peter et al. [eds.], Raza, etnicidad y sexualidades, Colombia: Universidad Nacional de Colombia.

Restrepo, Eduardo (2004), Teorías contemporáneas de la etnicidad: Stuart Hall y Michel Foucault, Colombia: Universidad del Cauca.

Segato, Rita (2007), La Nación y sus Otros. Raza, etnicidad y diversidad religiosa en tiempos de Politicas de la Identidad, Argentina: Prometeo.

Segato, Rita (2016), "Claves para una política femenina en dirección al fin de la prehistoria patriarcal”, conferencia dictada en el III Congreso de Estudios Poscoloniales "Interrupciones desde el sur: habitando cuerpos, territorios y saberes”, 12-15 diciembre, Argentina (inédito).

Sieder, Rachel [ed.] (2002), Multiculturalism in Latin America. Indigenous rights, Diversity and Democracy, Inglaterra: Institute of Latin American Studies.

Sleeter, Christine y Grant, Carl (1988), Making choices for multicultural education: Five approaches to race, class, and gender, Estados Unidos: Merrill.

Staab, Silke y Mahler, Kristen (2005), "Nanny Politics. The dilemas of working women's empowerment in Santiago, Chile”, en International Feminist Journal of Politics, vol. 7, núm. 1, Reino Unido: Taylor and Francis.

Steiner, Carol y Reisinger, Yvette (2006), "Understanding existential authenticity”, en $A n$ nals of Tourism Research, vol. 33, núm. 2, Holanda: Elsevier.

Stefoni, Carolina y Fernández, Rosario (2011), "Mujeres inmigrantes en el trabajo doméstico. Entre el servilismo y los derechos", en Stefoni, Carolina [ed.], Mujeres Inmigrantes en Chile. ¿Mano de obra o trabajadoras con derechos?, Chile: Universidad Alberto Hurtado.

Stoler, Ann-Laura (2009), Along the Archival Grain: Epistemic Anxieties and Colonial Common Sense, Estados Unidos: Princeton University Press.

Stoler, Ann-Laura (2013), La chair de l'empire. Savoirs intimes et pouvoirs raciaux en régime colonial, Francia: La Découverte.

Ulloa, Astrid (2005), "Las representaciones sobre los indígenas en los discursos ambientales y de desarrollo sostenible", en Mato, Daniel [coord.], Políticas de economía, ambiente y sociedad en tiempos de globalización, Venezuela: Universidad Central de Venezuela.

Van Cott, Donna-Lee (2000), The friendly liquidation of the past: the politics of diversity in Latin America, Estados Unidos: University of Pittburgh Press.

Varikas, Eleni (1998), “Sentiment national, genre, ethnicité. Questions et impensés”, en Tumultes, núm. 11, Francia: Université Paris Diderot.

Varikas, Eleni (2007), Les rebuts du monde, Francia: Stock.

Vera, Antonieta (2014), "Moral, representación y feminismo mapuche: elementos para formular una pregunta”, en Polis, núm. 11, Chile: Universidad de Los Lagos.

Vera, Antonieta (2016), “Guardianas de la cosmovisión de un pueblo: representaciones político-religiosas de la autenticidad mapuche", ponencia presentada en el Congreso Latin American Studies Association (LASA), Nueva York, Estados Unidos, 27-30 de mayo (inédito).

Wade, Peter (2009), Race and sex in Latin America, Inglaterra: Pluto Press. 
Wade, Peter (2011), "Multiculturalismo y racismo", en Revista Colombiana de Antropología, vol. 47, núm. 2, Colombia: Instituto Colombiano de Antropología e Historia.

Wang, Ning (1999), "Rethinking authenticity in tourism experience", en Annals of Tourism Research, vol. 26, núm. 2, Holanda: Elsevier.

Zárate, María-Soledad (2007), Dar a luz en Chile, Siglo XIX. De la "ciencia hembra" a la ciencia obstétrica, Chile: DIBAM.

Zermeño-Padilla, Guillermo (2008), "Del mestizo al mestizaje: arqueología de un concepto", en Memoria y Sociedad, vol. 12, núm. 24, Colombia: Pontificia Universidad Javeriana.

Zizek, Slavoj (1998), "Multiculturalismo, o la lógica del capitalismo multinacional", en Jameson, Fredric y Zizek, Slavoj, Estudios culturales. Reflexiones sobre el multiculturalismo, Argentina: Paidós.

Antonieta Vera. Doctora en Ciencia Política por la Université Paris VIII. Académica de la Escuela de Ciencia Política y Relaciones Internacionales de la Universidad Academia Humanismo Cristiano y de la Universidad de Chile (CEGECAL). Líneas de investigación: políticas de la identidad en América Latina, teoría feminista decolonial y estudios interseccionales. $\mathrm{Pu}$ blicaciones recientes: Vera, Antonieta [ed.], Malestar Social y Desigualdades en Chile. Santiago: Ediciones Universidad Alberto Hurtado (2017); Vera, Antonieta, "La superioridad moral de la mujer: sobre la norma racializada de la femineidad en Chile", en Historia y Politica, núm. 36, España: Universidad Complutense (2016); Vera, Antonieta, "Excepcionalismo y performance marianista en Gabriela Mistral”, en Aisthesis, núm. 57, Chile: Universidad Católica (2015).

Isabel M. Aguilera. Doctora en Antropología Social y Cultural por la Universidad de Barcelona. Académica del Departamento de Antropología de la Universidad de Tarapacá, Arica, Chile. Líneas de investigación: antropología de la alimentación, Estados nacionales y formaciones de alteridad. Publicaciones recientes: Aguilera, Isabel, De la cocina al estado nación. El ingrediente mapuche, Barcelona: Icaria-Observatorio de la Alimentación (2016); Aguilera, Isabel, "Devenir Típico: una aproximación genealógica al fenómeno merkén en Chile", en RIVAR, vol. 3, núm. 8, Santiago: Instituto de Estudios Avanzados de la Universidad de Santiago (IDEA-USACH) (2016).

Rosario Fernández. Candidata a Doctora en Sociología y Profesora Asociada del Departamento de Sociología de Goldsmiths, Universidad de Londres. Líneas de investigación: género, racismo, trabajo doméstico y migraciones. Publicaciones recientes: Fernández, Rosario, “Trabajo doméstico pagado: la 'solución perfecta' para la 'familia feliz' en Chile”, en Pavez, Jorge [ed.], 
(Des) Orden de género. Politicas y mercados del cuerpo en Chile. Santiago de Chile: CRANN Editores (2017); Ambiado, Constanza y Fernández, Rosario, "Sobre inmigrantes latinoamericanos en la televisión chilena: estigmas y fronteras en las narrativas audiovisuales”, en Revista Comunicación, núm. 10, vol. 1, España: Universidad de Sevilla (2012); Stefoni, Carolina y Fernández, Rosario, "Mujeres inmigrantes en el trabajo doméstico. Entre el servilismo y los derechos", en Stefoni, Carolina [ed.], Mujeres migrantes en Chile. ¿Mano de obra o trabajadoras con derechos?, Santiago de Chile: Ediciones Universidad Alberto Hurtado (2011).

Recepción: 05 de junio de 2017.

Aprobación: 27 de septiembre de 2017. 